\title{
Seroprevalence of brucellosis in cattle in selected area of Bangladesh and comparison between Rose Bengal test and i-ELISA used for the screening of brucellosis
}

\author{
Md. Siddiqur Rahman ${ }^{1 *}$, Amitavo Chakrabartty ${ }^{1}$, Md. Taohidul Islam ${ }^{1}$, \\ Roma Rani Sarker ${ }^{1}$, ME Alam ${ }^{1}$, Muhammad Jasim Uddin ${ }^{1}$, \\ Laila Akther ${ }^{2}$, Hee-Jong Song ${ }^{3}$ \\ ${ }^{I}$ Department of Medicine, Faculty of Veterinary Science, Bangladesh Agricultural University, Mymensingh 2202, Bangladesh \\ ${ }^{2}$ Department of Livestock Services, Krishi Khamar Sarak, Farmgate, Dhaka 1215, Bangladesh \\ ${ }^{3}$ Korea Zoonoses Research Institute, Chonbuk National University, Jeonju 561-756, Korea
}

(Received 20 April 2012; revised 11 June 2012; accepted 13 June 2012)

\section{Abstract}

Brucellosis, a bacterial zoonoses caused by the genus Brucella is responsible for abortion and infertility in cow. Brucellosis is causing economic loss in dairy industries and prevalent worldwide including Bangladesh but limited studies are devoted to determine the prevalence and its association with reproductive factors of dairy cows in Bangladesh. Therefore, the present study was conducted to determine the seroprevalence of brucellosis in dairy cattle using screening test Rose Bengal test (RBT) and the positive sera were further confirmed by indirect- ELISA. For this purpose, a total of 400 serum samples from dairy cows with history of abortion and various reproductive disorders were collected from the Kurigram district of Bangladesh for the detection of Brucella antibody. The overall prevalence of brucellosis in dairy cattle was $2.25 \%$. Brucellosis in cases of abortion and repeat breeding was $8.3 \%$ and $2.8 \%$, respectively. The results shows higher prevalence of brucellosis in cases of abortion followed by repeat breeding, while there was no seropositive cases from other reproductive disorders. Age-wise seroprevalence was found $3.0 \%$ in $2 \sim 3$ years age group and $2.0 \%$ in $4 \sim 8$ years age group. The prevalence of brucellosis in indigenous and cross-bred cattle was 3.6\% and $1.7 \%$, respectively. All the animals detected positive to brucellosis by RBT were not found to be positive by i-ELISA. However, the RBT might be a suitable screening test for the diagnosis of Brucella infection in field condition in Bangladesh. These data will help to develop effective disease prevention strategies.

Key words : Brucellosis, Cattle, Rose Bengal test, i-ELISA, Bangladesh

\section{INTRODUCTION}

Brucellosis is a zoonotic disease caused by gram-negative bacteria Brucella that are pathogenic for a wide variety of animals and human beings. The main domestic animals affected are cattle, sheep, goats, and pigs (Young, 1995). While the genus Brucella has six species on the basis of host specificity, B. abortus caused

\footnotetext{
*Corresponding author: Md. Siddiqur Rahman, Tel. +88-091-67401-6 (Ext. 2390), Fax.+88-091-61510, E-mail.prithu102@yahoo.co.uk
}

abortion and infertility in dairy cows. It also causes significant reproductive disorders in sexually mature cattle manifested by late term abortions, inflammation of the genital organs and fetal membrane, fetal death, sterility, and formation of localized lesions in the lymphatic system and joints (Probert et al, 2004). Brucellosis is an occupational hazard that affects farmers and their families, abattoir workers, farm labor, slaughter-house workers, butchers and veterinarians (Yagupsky and Baron, 2005). 
Brucellosis is endemic worldwide including Bangladesh (Amin et al, 2004; Das et al, 2008). But often a neglected disease. In Bangladesh it was first reported in cattle (Mia and Islam, 1967), and in human (Rahman et al, 1983). Islam et al (1983) estimated the annual economic loss in Bangladesh due to bovine brucellosis in indigenous cows as 720,000 EUR (total) and 12,000 EUR per 1,000 cross-bred cows and a total of 276,000,000 EUR in cross-bred cows. There are a lot of undiagnosed cases of abortion, stillbirth and retained placenta which are thought to be due to brucellosis and these have a significant impact on the development of livestock in Bangladesh (Islam et al, 1983; Rahman et al, 2006; Rahman, 2010).

However, in spite of its importance, few studies are devoted to determine the prevalence of brucellosis in dairy cattle in Bangladesh. Therefore, it is necessary to determine the prevalence of brucellosis and its association with different reproductive disorders in dairy cattle.

The diagnosis of brucellosis is confirmed by isolation of Brucella spp. by bacteriological culture or by the detection of an immune response by serological test to its antigens (Orduña et al, 2000). But the diagnosis of brucellosis based exclusively on Brucella isolation presents several drawbacks. The slow growth of Brucella may delay diagnosis for more than 7 days and also, the sensitivity is often low, ranging from 50 to $90 \%$ depending on disease stage, Brucella spp., culture medium, quantity of bacteria and culture technique employed (Gotuzzo et al, 1986). Hence, the serological tests are important for diagnosis of brucellosis. Serological test like the Rose Bengal test (RBT), slow agglutination test (SAT), mercaptoethanol test and enzyme linked immunosorbent assay (ELISA) and complement fixation test (Islam, 1983; Ferreira et al, 2003) are generally used for the detection of Brucella infection in animal. RBT has been widely used and more useful as a screening herd test (OIE, 2009). However, it is necessary to find out an appropriate test that could be perform easily with less expense but has high sensitivity in field condition. To the best of knowledge, there is no such study is conducted in filed condition in Bangladesh. Therefore, the aim of this study was to determine the prevalence of the brucellosis in dairy cattle in selected regions (six upazilas of Kurigram district) in Bangladesh by detecting the Brucella antigen by RBT and i-ELISA.

\section{MATERIALS AND METHODS}

A total of 400 blood samples were collected from dairy cattle aged over $\geq 2$ years with the history of repeat breeding, anoestrus, retention of placenta, dystocia, prolapse of uterus and abortion of six upazilas in Kurigram district. Total cattle population in Kurigram district is 0.71 million and there are 457 registered dairy farms in Kurigram district. There is a corridor in Kurigram Sadar for importation of cattle from India (DLO Office Kurigram, 2007). There are lots of cases for abortion, repeat breeding, retention of placenta and other reproductive disorders are frequently reported in different regions in Kurigram district which are thought to be for brucellosis. So far literature reviewed, there was no survey carried out in Kurigram district for the determination of prevalence of brucellosis in dairy cattle. Therefore, six upazilas of Kurigram district was considered for this study. Number of serum samples collected from Ulipur, Rajarhat, Kurigram Sadar, Nageswari, Roumari, and Chilmari upazilas were 100, 120, $90,50,20$, and 20, respectively. The study was conducted for a period of 6 months from June, 2011 through November, 2011 in the Department of Medicine, Faculty of Veterinary Science, Bangladesh Agricultural University, Mymensingh.

\section{Rose Bengal Test (RBT)}

All the blood samples were processed for serum preparation and then subjected to RBT as a screening test using B. abortus antigen (obtained from Dae Sung Microbiological lab, South Korea). The test was performed according to the procedure as described by the OIE (2009).

\section{Indirect enzyme linked immunosorbent assay (i-ELISA)}

All the samples found to be positive in RBT were 
further confirmed using i-ELISA in the OIE reference laboratory for brucellosis in Jena, Germany. The assay was performed according to the protocol provided by the manufacturer's instructions (Svanova Biotech AB, Uppsala, Sweden).

\section{Statistical analysis}

The Chi-square test was employed to find out the significant differences in the prevalence in terms of age, breed and different reproductive disorders of cattle.

\section{RESULTS}

\section{Seroprevalence of brucellosis}

The overall prevalence of brucellosis was $2.25 \%$ (9/400) in dairy cattle of six upazilas of Kurigram district. It is to be mentioned that the doubtful negative samples $(n=22)$ that were tested in the OIE reference laboratory for brucellosis in Jena, Germany gave also negative reaction. The highest prevalence $(5.6 \%)$ was recorded in Kurigram Sadar upazila while $2.0 \%$ and $1.7 \%$ were recorded in Ulipur and Rajarhat upazilas, respectively. However, there was no significant difference in the prevalence of these three upazilas. No positive reactors were found in three other upazilas. Results of age-wise seroprevalence of brucellosis revealed that the prevalence was $3.0 \%$ in $2 \sim 3$ years age group and $2.0 \%$ in 4 8 years age group. With respect to various reproductive problems, the number of positive reactors was recorded and it was found that there were no positive reactors with the history of anoestrus, dystocia, prolapse of uterus and retention of placenta. However $2.8 \%$ and $8.3 \%$ prevalence was recorded in dairy cattle with history of repeat breeding and abortion. Breed-wise seroprevalence recorded in the study revealed that the prevalence of brucellosis in indigenous and cross-bred dairy cattle was $3.6 \%$ and $1.7 \%$ respectively and there was no significant difference in the prevalence between the types of breed (Table 1).

Notably, the nine RBT positive samples including 22 doubtful samples were tested by using i-ELISA. The re-
Table 1. Seroprevalence of brucellosis in Kurigram district based on different demographic factors

\begin{tabular}{lccc}
\hline \multicolumn{1}{c}{ Upazilas } & $\begin{array}{c}\text { No. of serum } \\
\text { samples tested }\end{array}$ & $\begin{array}{c}\text { No. of RBT } \\
\text { positive } \\
\text { reactors }\end{array}$ & $\begin{array}{c}\text { Prevalence } \\
(\%)\end{array}$ \\
\hline Ulipur & 100 & 2 & $2.0^{*}$ \\
Rajarhat & 120 & 2 & $1.7^{*}$ \\
Kurigram Sadar & 90 & 5 & $5.6^{*}$ \\
Nageswari & 50 & 0 & - \\
Rowmari & 20 & 0 & - \\
Chilmari & 20 & 0 & - \\
Age & & & \\
2 3 years & 100 & 3 & $3.0^{*}$ \\
4 8 years & 300 & 6 & $2.0^{*}$ \\
Reproductive problems & & & \\
Repeat breeding & 250 & 7 & $2.8^{*}$ \\
Abortion & 24 & 2 & $8.3^{*}$ \\
Anoestrus & 64 & 0 & 0 \\
Dystocia & 32 & 0 & 0 \\
Prolapse of uterus & 8 & 0 & 0 \\
Retention of placenta & 22 & 0 & 0 \\
Breed & & & $3.6^{*}$ \\
Indigenous & 289 & 5 & $1.7^{*}$ \\
Cross & & & \\
\hline$*$
\end{tabular}

*Values with same superscripts within a column do not differ significantly at $5 \%$ level of significance.

sults showed that all the doubtful samples were negative in the case of i-ELISA. Additionally, three samples out of the nine samples detected positive by RBT were negative in the case of i-ELISA.

\section{DISCUSSION}

Various studies have been conducted in Bangladesh to determine the prevalence of the disease in bovine species (Rahman et al, 2006; Nahar and Ahmed, 2009; Kadir, 2010) but the present study is based mainly on non-random sampling techniques from dairy cattle with reproductive problems. Only animals aged over $\geq 2$ years were tested since brucellosis is a disease of sexually mature animals. The RBT is considered as the most widely used test for the screening and monitoring of brucellosis in dairy cattle (OIE, 2009). In the last decade, several indirect enzyme linked immunosorbent assays (ELISA) have been developed and successfully tested on sera samples.

The present study was designed to determine the se- 
roprevalence of the disease in the dairy cattle of Kurigram district using RBT and to compare the RBT with i-ELISA. The serum samples from selected dairy cattle with history of reproductive problems were analyzed with RBT which revealed prevalence of $2.25 \%$. This finding is in agreement with the reports of some research (Amin et al, 2004; Kadir, 2010; Rahman et al, 2006) who reported the prevalence $2 \%, 2.4 \%, 2.66 \%$ and $2.72 \%$, respectively. The result is lower than the findings of Nahar and Ahmed (2009) who reported $4.5 \%$. This variation in the prevalence may be due to variation in the age, breed, sex, pregnancy status of the animal, study area, hygienic condition, breeding techniques, herd size, reproductive diseases and diagnostic tests applied (Kebede, 2008). The prevalence in Kurigram Sadar upazila is higher $(5.6 \%)$ than Ulipur $(2.0 \%)$ and Rajarhat (1.7\%) upazilas. The difference in the prevalence among the upazilas was not statistically significant.

Age-wise disease prevalence was found $3.0 \%$ in $2 \sim 3$ years age group while $2.0 \%$ in $4 \sim 8$ years age group. The difference between the groups was not statistically significant. In contrast to the findings of the present study, Rahman et al (2011) reported the prevalence of brucellosis in the cow aged 2.5 4 years as $1.45 \%$ while in the cows over four years of age as $5.31 \%$. Similarly, Amin et al (2004) reported 2.3\% and 4\% prevalence in the $<4$ and $>4$ years age group, respectively. Age-wise prevalence has also been studied by Abubakar et al (2010) who showed that the incidence of brucellosis increased with age, and the incidence is high in sexually mature animals. The prevalence of brucellosis was $2.8 \%$ and $8.3 \%$ in dairy cattle with history of repeat breeding and abortion. The present findings are in agreement with Rahman et al (2006) who reported brucellosis to be higher in cattle with a history of abortion (15\%) as compared to those with a history of returns to service $(1.45 \%)$. In this study, the prevalence of brucellosis was $3.6 \%$ and $1.7 \%$ in the indigenous and cross-bred cattle, respectively. The difference between the two groups was not statistically significant. Akbarmehr and Ghiyamirad (2011) reported that there exists differences in the prevalence of brucellosis in different breeds, but statistically not significant.
In the present study, i-ELISA in conjunction with RBT was employed to compare the efficacy, testing of 31 samples by both RBT and i-ELISA revealed that 3 samples were positive and 22 were negative by both the tests while additional six samples were negative by i-ELISA only. Chakraborty et al (2000) reported lower sensitivity (56.96\%) and higher specificity (96.77\%) of RBT, whereas Singh et al (2004) found $88.46 \%$ sensitivity and $97.75 \%$ specificity. On the other hand, Ahmed et al (2011) reported higher sensitivity (100\%) and specificity (94.92\%) of RBT. Additionally, higher sensitivity and lower specificity of RBT were also obtained by Muma et al (2007).

In spite of the facts, we could conclude that RBT could be an important screening test for brucellosis in Bangladesh and the doubtful and positive cases could be further validated or confirmed using i-ELISA. This study showed that prevalence of brucellosis is related to the reproductive problems of cows in Bangladesh. These results will help the livestock department to design preventive measure for brucellosis which is causing huge economic losses in Bangladesh.

\section{REFERENCES}

Abubakar M, Javed Arshed M, Hussain M, Ehtisham-ul-Haq, Ali Q. 2010. Serological evidence of Brucella abortus prevalence in Punjab province, Pakistan-a cross-sectional study. Transbound Emerg Dis 57: 443-447.

Ahmed M, Islam MA, Khatun MM, Baek BK. 2011. Evaluation of four serological tests for the detection of brucellosis in goats and cattle under the field condition of Bangladesh. Asian J Biol Sci 4: 477-482.

Akbarmehr J, Ghiyamirad M. 2011. Serological survey of brucellosis in livestock animals in Sarab City (East Azarbayjan province), Iran. African J Microbiol Res 5: 12201223.

Amin KMR, Rahman MB, Sarkar SK, Kabir SML, Akand MSI. 2004. Serological epidemiology of brucellosis in cattle of the Mymensingh district of Bangladesh. J Anim Vet Adv 3: 898-900.

Chakraborty M, Patgiri GP, Sarma DK. 2000. Use of Rose Bengal plate test, serum agglutination test and indirect ELISA for detecting brucellosis in bovines. Indian $\mathrm{J}$ Comp Microbiol Immunol Infect Dis 21: 24-25.

Das T, Ershaduzzaman M, Islam KK, Haque MM, Rahman MM, Islam KBMS. 2008. Surveillance of Brucella melitensis and Brucella abortus from aborted Bengal goats in 
Bangladesh. Res J Vet Sci 1: 28-36.

Ferreira AC, Cardoso R, Travassos Dias I, Mariano I, Belo A, Rolão Preto I, Manteigas A, Pina Fonseca A, Corrêa De Sá MI. 2003. Evaluation of a modified Rose Bengal test and an indirect enzyme linked immunosorbent assay for the diagnosis of Brucella melitensis infection in sheep. Vet Res 34: 297-305.

Gotuzzo E, Carrillo C, Guerra J, Llosa L. 1986. An evaluation of diagnostic methods for brucellosis-the value of bone marrow culture. J Infect Dis 153: 122-125.

Islam A, Haque M, Rahman A, Rahman MM, Rahman A, Haque F. 1983. Economic losses due to brucellosis among cattle in Bangladesh. Bangl Vet J 17: 5762.

Kadir 2010. Seroprevalence of Brucellosis in cattle in some of the selected areas of Naogaon District. M.S. Thesis, Department of Medicine, Bangladesh Agricultural University, Mymensingh.

Kebede T, Ejeta G, Ameni G. 2008. Seroprevalence of bovine brucellosis in smallholder farms in central Ethiopia (Wuchale-Jida district). Revue de Medecine Veterinaire 159: 3-9.

Mia AS, Islam H. 1967. A preliminary study on the incidence of bovine infertility and economic loss caused by it. Pakistan Vet J 1: 12-15.

Muma JB, Toft N, Oloya J, Lund A, Nielsen K, Samui K, Skjerve E. 2007. Evaluation of three serological tests for brucellosis in naturally infected cattle using latent class analysis. Vet Microbiol 125: 187-192.

Nahar A, Ahmed MU. 2009. Sero-prevalence study of brucellosis in cattle and contact human in Mymensingh district. Bangl J Vet Med 7: 269-274.

OIE. 2009. Bovine brucellosis. Manual of diagnostic tests and vaccines for terrestrial animals. http://www.oie.int/ fileadmin/Home/eng/Health_standards/tahm/2.04.03_ BOVINE_BRUCELL.pdf.

Orduña A, Almaraz A, Prado A, Gutierrez MP, Garcia-Pascual A, Dueñas A, Cuervo M, Abad R, Hernández B, Lorenzo B, Bratos MA, Torres AR. 2000. Evaluation of an immunocapture-agglutination test (Brucellacapt) for the seodiagnosis of human brucellosis. J Clin Microbial 38: 4000-4005.

Probert WS, Schrader KN, Khuong NY, Bystrom SL, Graves MH. 2004. Real-time multiplex PCR assay for detection of Brucella spp., B. abortus, and B. melitensis. J Clin Microbiol 42: 1290-1293.

Rahman MM, Choudhury TIMFR, Rahman A, Haque F. 1983. Seroprevalence of human and animal brucellosis in Bangladesh. Indian Vet J 60: 165.

Rahman MS, Han JC, Park J, Lee JH, Eo SK, Chae JS. 2006. Prevalence of brucellosis and its association with reproductive problems in cows in Bangladesh. Vet Rec 159: 180-182.

Rahman MS. 2010. Brucellosis: a great constraint for development of livestock. Bangl Dairy Poul 5: 18-19.

Rahman MS, Faruk MO, Her M, Kim JY, Kang SI, Jung SC. 2011. Prevalence of brucellosis in ruminants in Bangladesh. Veterinarni Medicina 56: 379-385.

Singh G, Sharma DR, Dhand NK. 2004. Seroprevalence of bovine brucellosis in Punjab. Indian Vet J 81:620-623.

Yagupsky P, Baron EJ. 2005. Laboratory exposures to Brucellae and implications for bioterrorism. Emerg Infect Dis 11: 1180-1185.

Young EJ. 1995. An overview of human brucellosis. Clin Infect Dis 21: 283-290. 